\title{
Review Article \\ Some Remarks on Bird's Brain and Behavior under the Constraints of Domestication
}

\author{
Julia Mehlhorn and Gerd Rehkämper \\ Research Group “Comparative Neurobiology and Evolutionary Research," Institute of Anatomy, University of Duesseldorf, \\ Universitätsstraße 1, 40225 Düsseldorf, Germany
}

Correspondence should be addressed to Julia Mehlhorn; julia.mehlhorn@uni-duesseldorf.de

Received 18 February 2013; Accepted 28 March 2013

Academic Editors: C. Cordero, Á. Kun, and D. Rau

Copyright (C) 2013 J. Mehlhorn and G. Rehkämper. This is an open access article distributed under the Creative Commons Attribution License, which permits unrestricted use, distribution, and reproduction in any medium, provided the original work is properly cited.

\begin{abstract}
The relationship between domestication and evolution is still a matter of discussion. In this review, we present some arguments for the assumption that domestication could be seen as an evolutionary process including the possibility that new species might evolve. In course of domestication, many breeds have been developed which show numerous alterations in different parameters such as body size, coloring, habitat, behavior, and brain size and composition. Here, we would like to give an overview particularly about alterations and varieties in (brain) morphology and behavior in domestic poultry and argue that these alterations could be seen as adaptations to the man-made environment.
\end{abstract}

\section{Introduction}

Domestication of animals is a recent event in human history and is defined as that condition wherein the breeding, care, and feeding of animals are more or less controlled by man [1]. The relationship between domestication and evolution is still a matter of discussion. On the one hand, domestication could be seen as an evolutionary and selective process where experiences and interactions with the environment (which includes man) play a significant role [2,3]. Hemmer [4] even expresses domestication as a special sort of evolution. On the other hand, two arguments are put forward against declaring domestication as a model of evolution. The first argument is that breeder's selection has replaced sexual mate choice by the animal. This phenomenon has been called "artificial selection" $[5,6]$. But by showing that mate choice of the breeder interacts with mate choices made by the animals itself, this argument is weakened [7]. The second argument is that there is still sexual attractiveness between the breeds of a domestic species and its wild ancestors [8]. This is not in line with the biological species concept (for review, see [9-11]) according to which species are freely interbreeding groups of individuals living in reproductive isolation from other groups of this kind. This argument neglects the phenomenon of hybridization and that it is more important to determine which genetic pairing is seen more often statistically and if there are nonrandom mating patterns [12].

Domestication is associated with several alterations and greater variability in a lot of traits in domestic animals if compared to their putative wild ancestors [2]. Although (or just because of this), there are authors like Hemmer [4] which claim domestication as "the decline of environmental appreciation." Empirical data on brain sizes which show smaller brains in dogs than in wolves or in domestic ducks in comparison to mallards seem to support this point of view $[13,14]$. Next to this "regression hypothesis" stands the "adaptation hypothesis" (e.g., [15-17]) which means that domestication is a dynamic evolutionary process and that all alterations during domestication are of adaptive character and due to changed conditions of a man-made environment. As measured by their worldwide distribution and their number (of living descendants), there is no doubt that domestic animals are very successful in their ecological niche "man."

During the course of domestication, many breeds have been developed which show alterations in, for example, body size, coloring, habitat, or behavior. Often these alterations differ from the wild but are as well adaptations to the new conditions. Generally speaking, a domestic animal occupies 
a niche in an artificial or altered environment [18]. Thus, a more suitable definition for domestication was to say that domestication should be defined as an adaptation to a man-made environment via population genetic mechanisms in which natural selection is largely replaced by artificial selection [19]. Overall, it is quite clear that domestication being a sort of human-driven evolution together with some nonadaptive changes produced several and very relevant adaptive changes.

According to Price $[2,20]$, domestication also involves genotypic adaptation. Thus, in the process of domestication, there is also the chance for the development of new species since new species are distinguished from older ones by alterations in gene frequencies and their consequences [21]. Thus, speciation could be profitably studied using domesticated animals. This is particularly true because an investigation of selective criteria is easier under the constraints of domestication than in the wild. This allowed Price [2] to conclude that "artificial selection is perhaps the best understood aspect of the domestication process."

Among the population of domesticated animals it is generally differentiated between economical strains and strains which are bred just for the pleasure of their breeder. The latter, the so-called fancy breeds, mostly do not perform high production of meat, milk, wool, eggs, or feathers but show as well numerous differences in comparison to their wild ancestors. The avian class presents a particularly strong variability and offers several possibilities regarding research.

In this review, we would like to give an overview about changes and varieties in (brain) morphology and behavior in domesticated birds (especially domestic poultry) and consider them under the constraints of evolutionary theory. Besides, it will give some support to (a) the adaptation hypothesis of domestication and (b) the idea that under domestication new species might evolve.

\section{Domestication of Birds}

When, where, and how domestication of different species of birds has taken place during the history of modern humans are intriguing questions that have attracted much attention from researchers in natural and cultural sciences. Probably, the first species of birds that was domesticated was the Greylag Goose (Anser anser), closely followed by the Rock Dove (Columba livia), the Red Junglefowl (Gallus gallus), and the Mallard (Anas platyrhynchos) [19, 22]. This occurred at least 3000 years B.C. and happened presumably in Southwest Asia, the Indus region, and Mesopotamia. Next to "exotic" birds like the Budgerigar (Melopsittacus undulatus), the Canary Bird (Serinus canaria), or the Zebra Finch (Taeniopygia guttata); more domesticated birds are, for example, the Muscovy Duck (Cairina moschata), the Turkey (Meleagris gallopavo) or later in time the Helmeted Guineafowl (Numida peleagris), or the Japanese quail (Coturnix japonica). The aims of the people maintaining and breeding birds are not exactly known. Two main reasons are suspected: for usable products and for esthetic purposes. Breeding birds provided a permanent supply of meat, eggs, grease, and of course of feathers which could be used for arrows, for ornamentation, and for the preparation of soft and warm beds and clothing. On the other hand, birds are also thought to have been used for religious sacrifice or just for pure pleasure because of their nice appearance or special behavioral features (e.g., fighting abilities of cocks, homing behavior of pigeons, or song capability of canaries).

Determining factors for the domestication of a species are a wide spectrum of food resources (seed or grass eaters), respectively, the capability of foraging on their own, the disposition of reproduction in captivity, the capacity for imprinting (which was important for the habituation to man), and the social structure which should allow to keep individuals of these species in large numbers and in small space (e.g., $[23,24])$. Next to the large amount of varieties in domestic animals, there are as well several very striking convergences and parallels in domesticated individuals of different species. Here, some examples are hypersexuality, loss of pigmentation, increase (or decrease) in body size, increase in subcutaneous fat deposition, and decrease in broodiness $[8,19,25]$. Another specific phenomenon of domestication is a reduction in brain size from wild to domestic animals, whereas this decrease is not uniform but varies in different species and in different brain parts. As observed for domestic mammals $[26,27]$, brains of highly encephalized bird species (which means large brains in relation to body size) are more affected by domestication than brains of species with smaller brains (e.g., birds of the duck or pigeon family show a low, but different level of cephalization [28]). Additionally, time of domestication and intensity of breeding or housing play a role for brain alterations in domestic animals.

But it has to be mentioned that a reduction of brain (parts) does not give information about the cognitive abilities of these birds. As well as "low encephalized" birds impress with complex cognitive abilities [29].

In the course of domestication, artificial selection leads to a large number of different breeds. Clutton-Brock [30] defines a breed as a group of animals from one species which differs from another group of the same species in typical heritable traits. Such a breed is a product of man's selection.

\section{Alterations in Brain and Behavior}

3.1. Chickens. Domestic fowl or chickens are known and kept throughout the world. They are the most widely utilized of all poultry species. As mentioned above, there are commercial and noncommercial breeds, whereas the commercial breeds are divided in layer breeds, meat breeds, and dual-purpose breeds. In commercial strains (genetic) variability is low, whereas in noncommercial strains, so-called fancy poultry, we find a higher genetic and morphological and behavioral variability as well. There exist breeds with alterations of feathering (curly feathers, feather crests, foot feathering, and prolongation of tail feathers, Figure 1), with morphological features (dwarfism, gigantism, shortened legs, rumplessness, and absence or increase of comb, Figure 2) or with peculiarities in behavior (breeds without broodiness, fighting/game breeds, or breeds with special crowing behavior, Figure 3). 


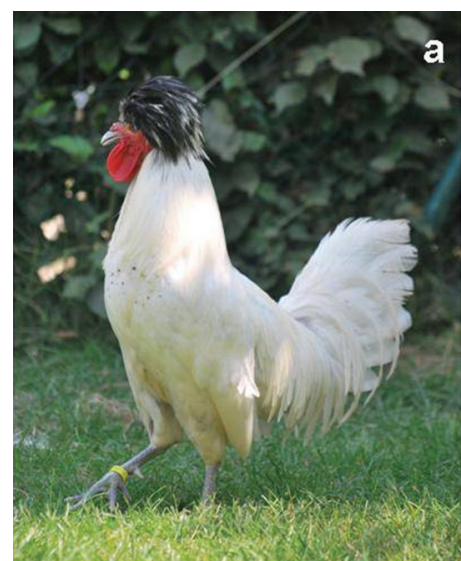

(a)

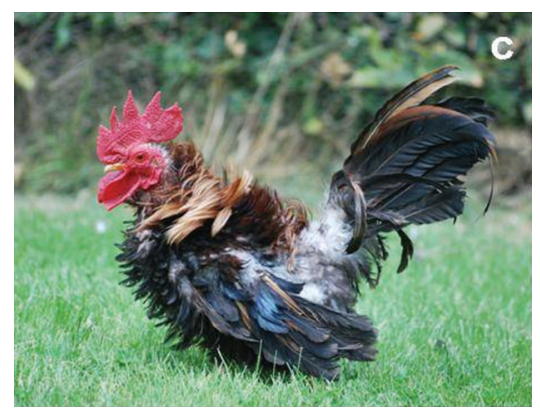

(c)

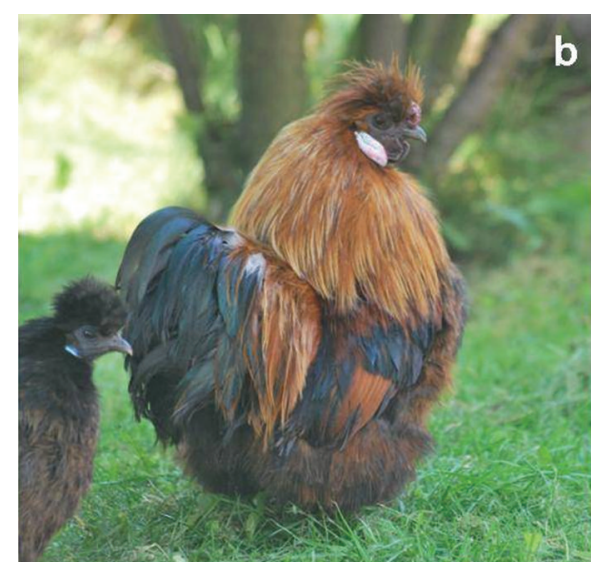

(b)

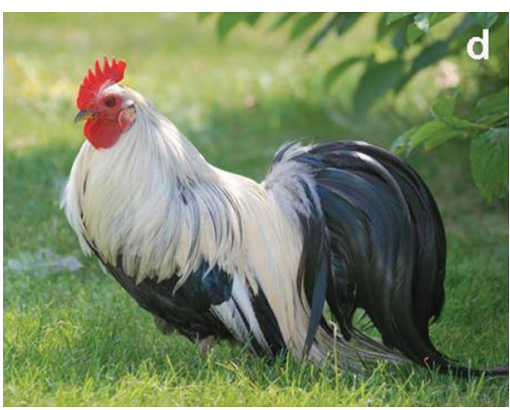

(d)

Figure 1: Different breeds of chicken with modifications of plumage. (a) Crested Polish chicken with feather crest. (b) Silky chicken with hair-like feathers. (c) Japanese Bantam with curly feathers. (d) Ohiki cock with elongated tail feathers.

And additionally, all these breeds are available in many different colors, a typical phenomenon of domestication [31].

Next to all these alterations, domestic chicken breeds show as well a large variability in brain morphology [32]. Here, the most astonishing example is the White Crested Polish Chicken (WCP, Figure 1(a)), a very extraordinary looking breed which is special in many more aspects than its appearance. WCPs belong to the group of crested chickens and are thought to have one of the longest histories of pure breeding among chickens [33]. The feather crest on their head is placed on a bony protuberance of frontal bones. Allometric brain comparison (consideration of the correlation of body weight with brain size) with other domestic chicken breeds shows that their brain is relatively larger and that this enlargement is partly due to enlarged ventricles. Additionally, the optic tract, diencephalon, apicale and densocellulare hyperpallium, mesopallium, and nidopallium are significantly enlarged in this breed [34]. Most of these structures are associated with cognitive abilities, and this is particularly interesting because up to date nobody knows what WCP does with their enlarged brain. To date, behavioral studies could not show an advantage in cognitive or learning behavior [35], and thus it needs more research to find out what WCP does exactly with their enlarged brain. The differences in appearance, brain size, and brain composition between WCP and other breeds are as large as the difference between species might be. Thus, WCP might be an ideal model for testing, whether speciation occurs under the conditions of domestication. One argument in favor of this is that in a cluster analysis with 12 brain parts as dimensions and in comparison with 7 other chicken breeds, the WCP stands out as well (together with another crested chicken breed, the Kraaikoppen (Figure 2(d)) [32]. Besides, it is proven that sexually mature females of WCP have a statistically significant preference for males of their own breed even if a male of another breed is presented simultaneously [7]. This could indicate the beginning of a sexual isolation which is defined as a precondition between different species. The authors concluded that WCP might be "on the way" to becoming species. This was also supported by the fact that WCPs tend to flock together as shown by shorter interindividual distances within WCP than across WCPs and different other chicken breeds [36]. A recent study could even show that the interindividual number of offsprings is higher within WCP than across WCPs and other chicken breeds [37].

An example for showing that alterations in external morphology could be very peculiar but must not necessarily alter brain morphology is the rumpless breed Araucana (Figure 2(b)). Here, a typical character is the so-called ear tufts. These are feather-covered epidermal appendages that project from the side of the chicken's head. These ear tufts are associated with an irregular external ear opening and a reduced external auditory canal and reduced middle ear fossa [38]. To determine whether these changes in the morphology are associated with changes in the brain, the 


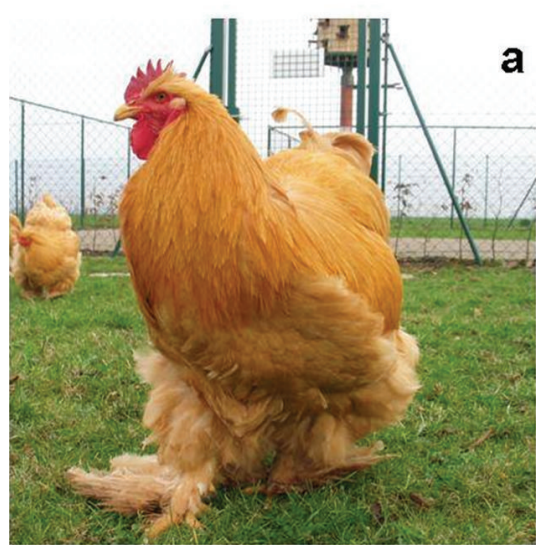

(a)

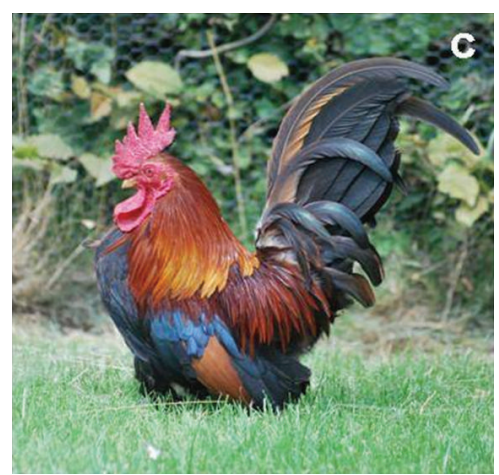

(c)

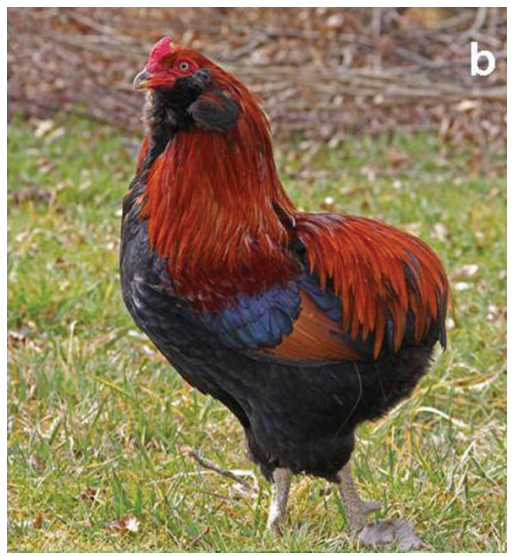

(b)

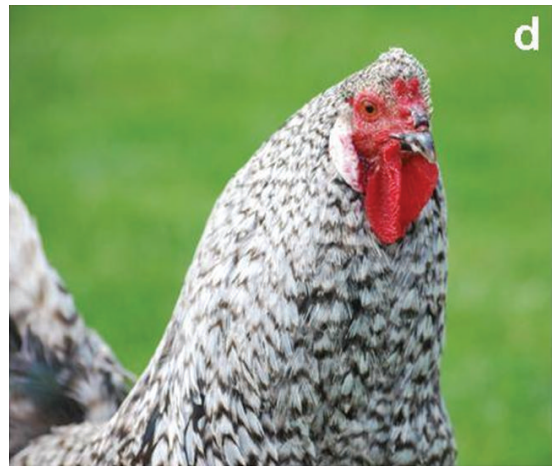

(d)

FIGURE 2: Different breeds of chicken with morphological modifications. (a) Cochin, the biggest breed of the world (cock up to 10 pounds) and with food feathering. (b) Araucana with ear tufts and shortened rump. (c) Japanese Bantam with shortened legs. (d) Kraaikoppen cock with decreased, antlers-like comb and small crest.

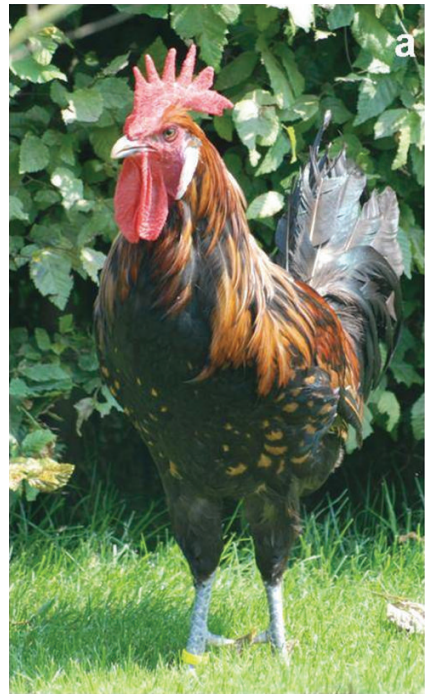

(a)

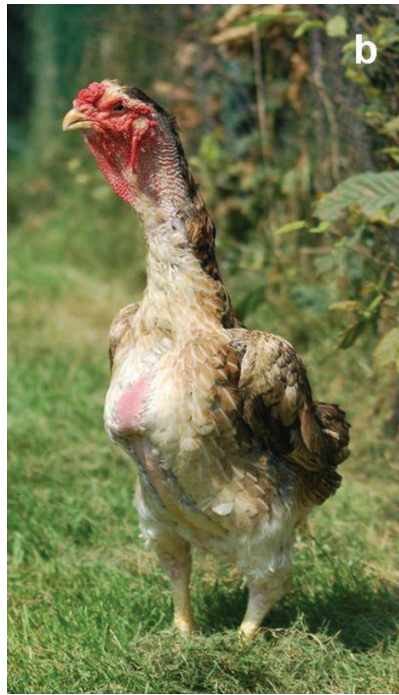

(b)

FIGURE 3: Different breeds of chicken with modifications in behavior. (a) Bergische Longcrowers which are bred for their long crowing. (b) Yamato Gunkei with typical reduced and tight feathering which was useful for cockfights. 
sizes of auditory nuclei in the brainstem of different chicken breeds were compared. Allometric comparisons revealed no size reductions of the angular, laminar, and superior olivary nuclei, but surprisingly a slight increase in the size of the magnocellular nucleus [34]. In contrast to this, the breed "Bergische Longcrower" (Figure 3(a)) which is famous because of its long and persistent crowing shows a decreased laminar nuclei (personal observation; [39]). Certainly, there is a correlation between brain (structure) size and its function $[16,40,41]$, but of course there are several parameters like number of neurons, cell proliferation, interstructural connections, and other parameters which could influence the function of a structure and which were not tested yet.

3.2. Pigeons. The 14 extant rock dove subspecies (Columba livia ssp.) [42] that represent the gene pool from which domestic pigeons are derived still inhabit the original terrain around the Mediterranean Sea and adjacent areas [43]. Domestic pigeons, however, are found worldwide [44]. And they show with more than 250 breeds solely in Germany the largest variability among domestic poultry. Nearly, all of these breeds are fancy breeds and thus were not bred just for commercial use. Only a few breeds which are used as well for meat production are an exception (e.g., Show King, Figure 4(c)). Within the fancy breeds, one can again differentiate between those breeds which show peculiarities in appearance (coloring, habitus, and feathering, Figure 4) and those which show peculiarities in (flying) behavior (ringbeaters or homing pigeons, Figure 5).

As observed in chickens, brain morphology is different not just between different pigeon breeds but as well in comparison to rock doves, their wild ancestor. Here, it could be observed that net brain volume, the volumes of cerebellum and telencephalon as a whole are significantly smaller in domestic pigeons $[17,45]$. But in contrast to this, the hippocampus (which is quite important for orientation and navigation) of homing pigeons is not just enlarged in comparison to other pigeon breeds but as well in comparison to wild rock doves. Since the beginning of breeding homing pigeons, they were strongly selected for fast and successful homing, and this does not lead just to a much better homing performance in comparison to rock doves (particularly if covering longer distances is required) [46] but with the enlarged hippocampus as well to the first documented brain component that is enlarged under the constraints of domestication compared to the wild form [17]. Thus, these data are in contrast to the predictions of the "regression hypothesis" (see above) and could be interpreted as a functional adaptation to homing. Another adaptation to homing is the increase of the olfactory bulb of homing pigeons in comparison to other pigeon breeds $[16,17]$. Next to visual and magnetic cues, olfactory cues are as well important for a good homing performance [47], and thus this finding is as well in line with the "adaptation hypothesis."

Additionally, homing pigeons are an example for mosaic evolution which means that subsystems of the brain might follow different trends of (size) alteration independently from others. Such mosaic evolution has been demonstrated particularly in the wild (mammals: e.g., [48]; birds: e.g., [41]) but now we see that mosaic evolution also exists under domestication. This strengthens our point of view that domestication can serve as a generalized model of evolution and that the so-called "artificial selection" under domestication and the so-called "directional selection" in the wild [49] can be treated in the same way. Here, homing pigeons are an evolutionary case study that demonstrates the influence of adaptive selection [50]. Only homing pigeons with a good homing performance were used for breeding, and thus these ones will have more offspring than their fellows.

Additionally, homing pigeons could help to get an insight into some problems of fundamental research. Here, we would like to mention the nature-nurture problem which means that it is often difficult to assess the extent to which a certain character is influenced by environmental or by genetic factors [51]. This is of particular difficulty with respect to brain (structure) size. Studies with homing pigeons reveal that pigeons with flying and navigational experience show a $11.2 \%$ larger hippocampus relative to the telencephalon compared to individuals without such experiences [52]. Additionally, the brain of homing pigeons with navigational experience shows more specialization of the left and right hemispheres (lateralization) in comparison to nonexperienced homing pigeons [53]. This confirms that the brain of homing pigeons is an example for mosaic evolution and indicates additionally that lateralization is correlated with individual life history (experience) and not exclusively based on heritable traits. The role of experience or other influencing factors must be investigated further if its evolution is of interest because modern evolutionary theory is primarily based on heritable traits rather than on acquired characters [54].

Besides, it seems to be that not just variability in outer appearance or behavior but as well in brain composition and brain plasticity of brains is generally larger in domestic species.

3.3. Ducks. In Asia, domestic ducks play an important role as meat and egg suppliers which leads to animal numbers comparable to chickens. Generally, diversity of breeds is not so large in ducks and is mainly visible in differences in size, color, habitus, and body posture (Figure 6). In Germany, for example, there are just approximately 20 duck breeds known including the commercial strains. Typical alterations of feathering like prolonged tail feathers, foot feathering, or curly feathers which are seen in chickens or pigeons do not occur in ducks. It is known that like in a lot of domesticated species, brain size in domestic ducks is reduced, but the size of certain brain structures is more variable in comparison to the mallard, their putative wild ancestor. Besides, the sex dimorphism of the brain size is lost in domestic ducks $[14,55]$. Reduction of rhombencephalic parts of the brain is greater than that in the prosencephalon, and within sensory centers, the nuclei of the trigeminal system undergo the most marked decrease [14]. The findings on the trigeminal system can easily be correlated with alterations of behavior, that is, the lack of dabbling, a behavioral pattern that lost its value during domestication. But regarding behavioral pattern, there are 


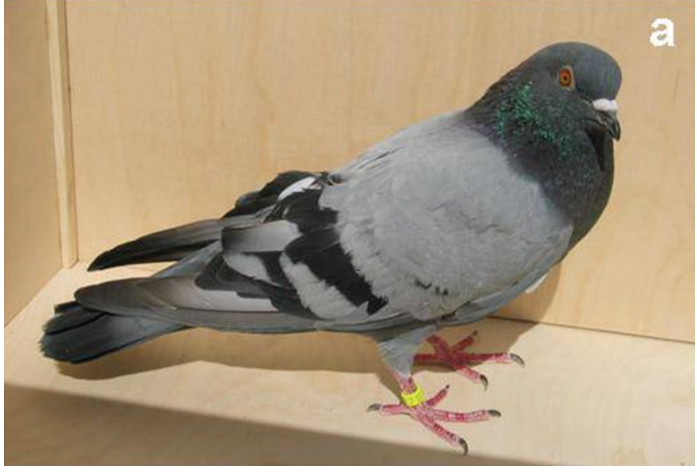

(a)

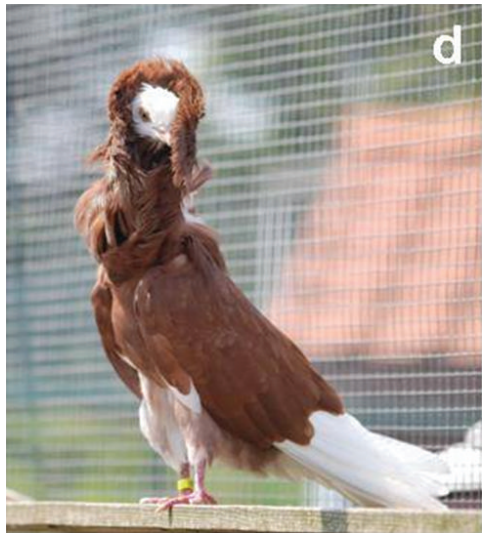

(d)

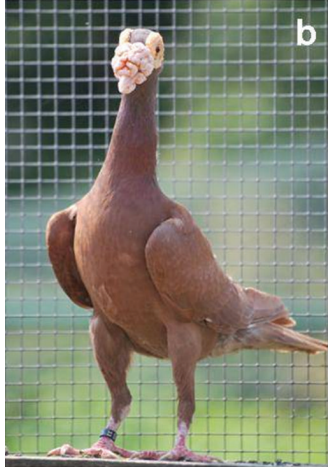

(b)

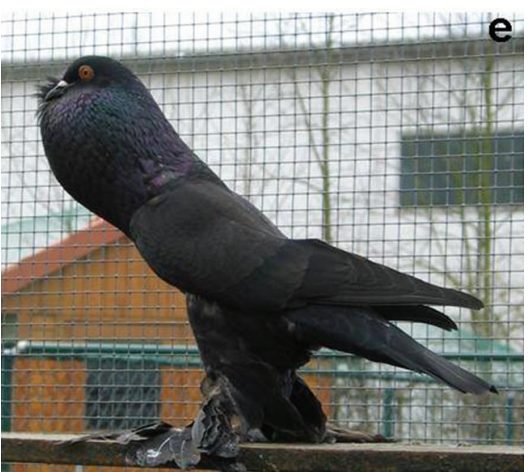

(e)

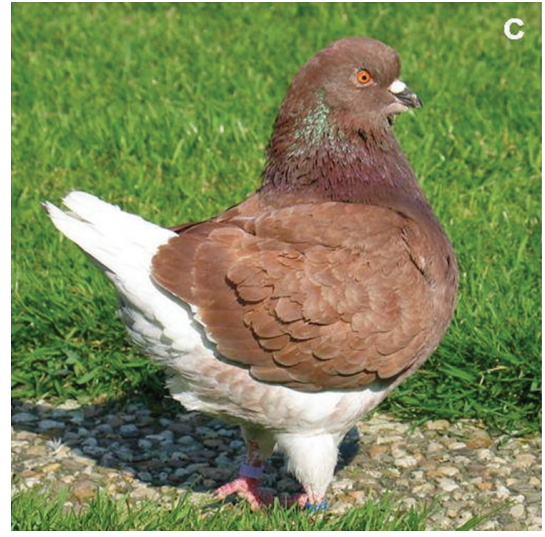

(c)

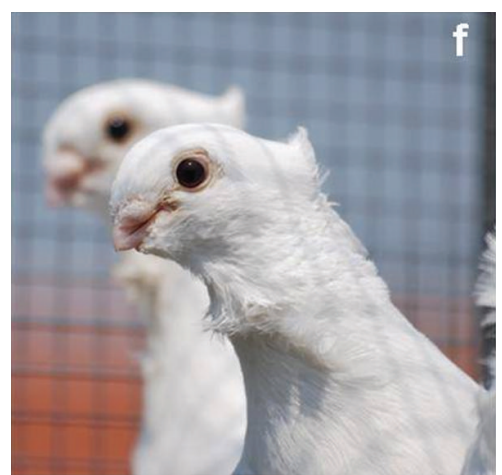

(f)

FIGURE 4: Different breeds of pigeons with modifications in morphology and/or plumage. (a) Rock Dove, the wild ancestor of all domestic pigeon breeds. (b) English Carrier with characteristic exuberances of the cere. (c) Show King which is bred for a high production of meat. (d) Jacobin with characteristic feather vortices. (e) Saxonian Cropper with increased and inflated crop and foot feathering. (f) Classic Old Frill with characteristic shortened beak, big eyes, and small crest.

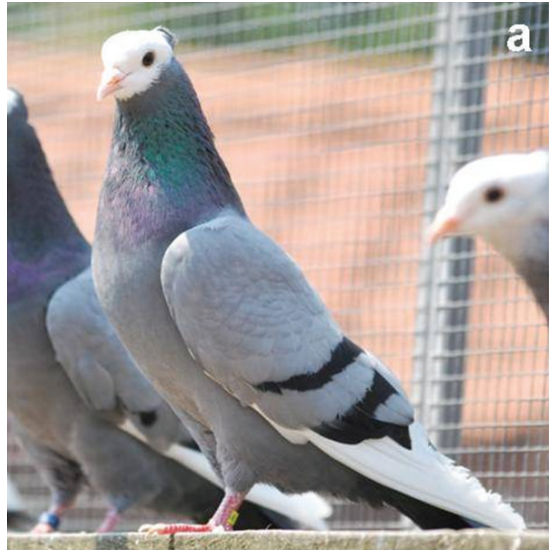

(a)

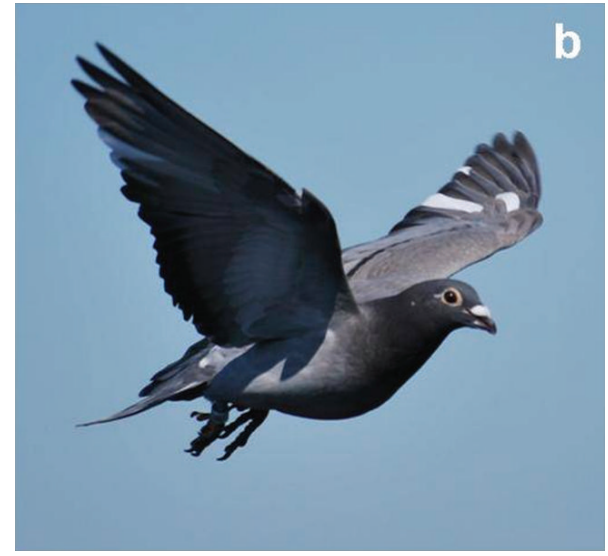

(b)

FIGURE 5: Different breeds of pigeons which are bred for their flying abilities. (a) Rhine Ringbeater which shows special flying behavior (wing clapping and circling) during mating. (b) Homing pigeon which is bred for a fast and successful homing. 


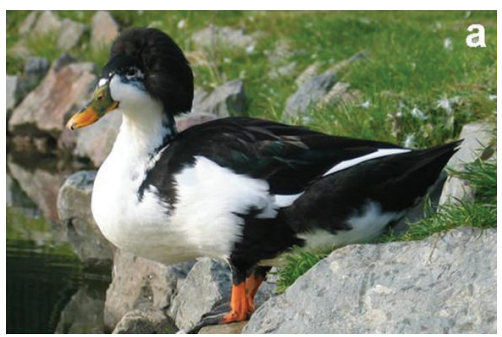

(a)

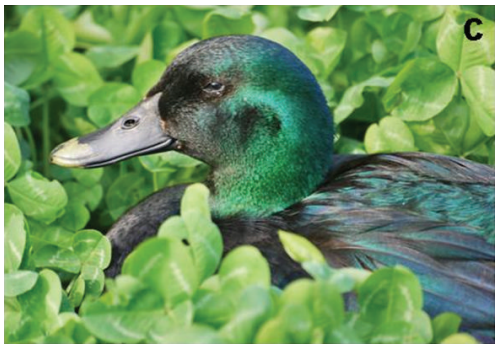

(c)

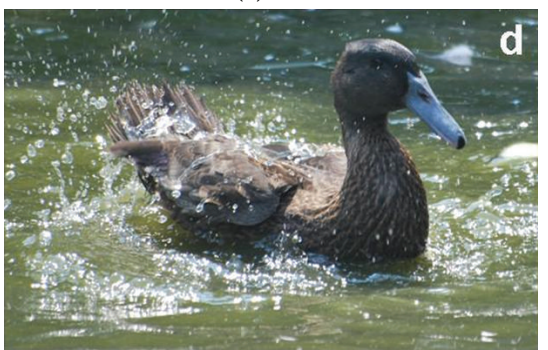

(d)

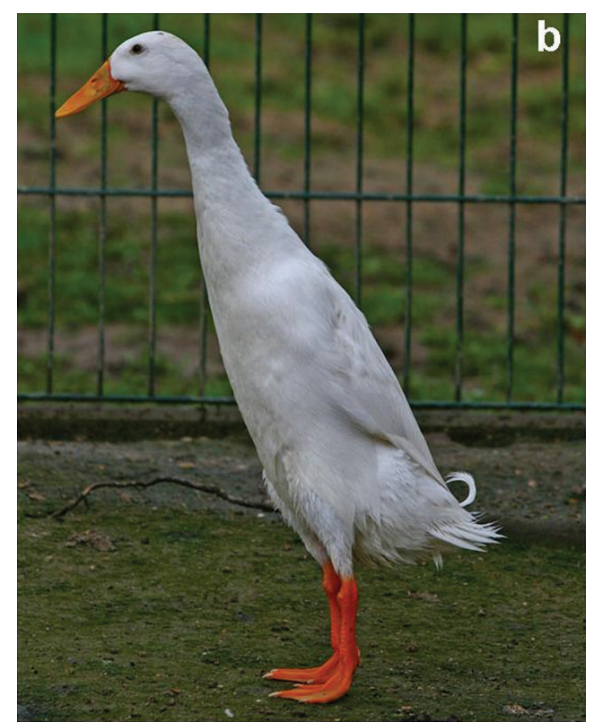

(b)

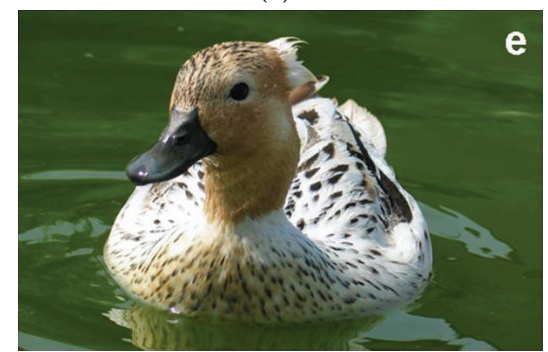

(e)

FIGURE 6: Different breeds of ducks. (a) Crested Duck with a typical feather crest. (b) Indian Runner Duck with characteristic upright body posture. (c) Black East Indian Duck with the typical green shining feathering. (d) Hookbill Duck: the bill will become more and more hooked over the years. (e) Call Duck, the smallest (and loudest) of the duck breeds.

data which show that there is no justification for the view that domestication must be a "degenerative" effect on, for example, social courtship behavior. Adult Pekin ducks perform all the species-typical social displays if keeping them in a natural setting during several breeding seasons [56]. Thus, the customary nonoccurrence of these displays in domestic animals is a function of the inhibiting or unfavorable environmental context in which the domestic birds usually find themselves.

In the different duck breeds, the only established alteration of feathering is a feather crest on the head which is most distinct in the breed Crested Duck (CR, Figure 6(a)). The CR is a duck breed with very conspicuous alterations on brain morphology. In contrast to crested chickens, their crest is not situated on a bony protuberance but on a cushion of fat and connective tissue in the parietal part of the skull. The cranium is often perforated under this cushion, and a lot of CRs bear a fat body inside the skull. Depending on its size and position in relation to the brain, this fat body could have deleterious effects on behavior. Occasionally, motor incoordination can be observed (demonstrated by a tottering walk), and some animals are even unable to right themselves after having fallen on their backs $[57,58]$. Additionally, hereditary aspects and high pre- and postnatal mortalities were discussed by some authors $[59,60]$. Analyzing the brain of CR showed that brain volume minus fat body was smaller compared to other duck breeds. In detail, cerebellum, apical hyperpallium, tegmentum, and olfactory bulb were significantly reduced in $\mathrm{CR}$, and obviously the behavioral deficits cannot be explained by the existence of a fat body but by functionally suboptimal cerebella and tegmenta. Fat body size seems to be a decisive factor [61].

Meanwhile, there are studies which show that a simple behavioral test helps to identify CR bearing a problematical fat body [62]. Now, these individuals can be excluded from breeding, and breeding experiments with test-selected ducks resulted in increased hatching rate, decreased number of (unhatched) ducklings with skull malformations, and decreased number of (hatched) ducks with malformations or motor incoordination as well [62]. Thus, this breed is not just an example for possible negative consequences of artificial selection during domestication but as well for the possibility to eliminate again negative characteristics in a relatively short time. Here, it becomes obvious that domestication could be seen as an evolutionary process and that artificial selection as well as natural selection might alter allele frequencies quickly. Because of the consequences for evolutionary theory, the discussion of a "punctuated equilibrium" might be of interest [63]. 
3.4. Other Poultry (Turkey, Goose, and Quail). Of course, there are a lot more domesticated bird species which cannot be all described in detail. Because of this and because of the fact that studies about particularly brain alterations of breeds of other poultry species are unfortunately rare, we would just like to mention a few.

Domestic turkeys are descendants of the wild turkey (Meleagris gallopavo) of North America and normally show a relatively low reproductive rate and limited agricultural utilization. With increased consumer demand for turkey and turkey products, the commercial interest is expanding, and next to this, there is as well a small group of fancy poultry breeders which are interested in different color types of domestic turkey [64]. Ebinger et al. [65] studied the intraspecific relationship between brain and eye weight to total body weight in native turkeys (Meleagris gallopavo) and domestic strains and revealed that sex differences in brain weight within wild turkeys are larger than in domestic turkeys. Generally, domestic turkeys show a large brain weight reduction in comparison to the wild form, namely 24-29\%. Here, the general reduction of prosencephalic brain parts is greater than that of the rhombencephalon. Additionally, in domestic turkeys, eye weight is by $27 \%$ smaller than in wild turkeys, and visual brain structures are reduced by $22-25 \%$ [66]. Turkeys belong to the family of Phasianidae, which has relatively small brains $[67,68]$, and normally the domesticated descendants of such animals show only slightly smaller brains than those of their wild ancestors (see above). Here, turkeys are an exception. Although the wild turkeys have small brains in relation to their body size, domestic turkeys show the highest degree of brain reduction measured in any of the domesticated birds so far. The authors explain this as a result of extreme breeding with strong selection for extremes of body weight and muscling. Thus, the brain is not so much smaller, but the body is so much larger in comparison to wild turkeys. The reduced sex dimorphism should be due to a reduction in the repertoire of sexual and courtship behavior which has dramatically changed by industrial stock breeding [69].

Another example for brain reduction during domestication is the domestic goose with the Greylag Goose (Anser anser) as their wild ancestor. Here, brain reduction of the domestic form just amounts to $16 \%$ in comparison to the wild form [70]. This is particularly due to the reduction of areas with multifunctional character. Besides, olfactory structures are different in shape and position compared to other birds, but not strongly reduced. Apparently, the influence of domestication on forebrain structures concerning olfaction and feeding is moderate in relation to other functional systems. However, the exact role of smell in geese, food seeking, or/and social behavior is not totally understood and needs more investigations. Generally, there is a limited variation in domestic breeds, and already Darwin [6] wrote that "hardly any other anciently domesticated bird or quadruped has varied so little." There are just a few modifications in plumage and/or body form, and no lethal genes have been reported [71].

Japanese quails (Coturnix japonica) were originally kept for song and are now farmed for meat and eggs. Its small size, inexpensive rearing requirements, rapid maturation compared with other domestic poultry, and adaptability to a wide range of husbandry conditions have also made this species popular as a laboratory animal for behavioral, developmental, and genetic research and for applied animal ethology and animal welfare [72].

Japanese quails belong as well to the family of Phasianidae but are much more susceptible to inbreeding depression as, for example, chicken [73]. A lot of studies about comparisons in different breeding lines exist. For example, Bessei et al. [74] selected quail chicks for high and low levels of motor activity in a novel environment and found lower levels of fear in the high-activity line. Other studies revealed that different strains and diallel cross between strains selected for nonfear-related traits have also indicated genetic variation in fear-related behavior. Strains selected for high or low mating frequency differed in their expression of the tonic immobility response, and strains selected for high or low levels of dust bathing behavior differed in their behavior in the timidity test [72]. A neurophysiological study of birds selected for long duration of the tonic immobility response indicated that the arcopallium (a large anatomically multifunctional area of the caudal ventrolateral telencephalon) with its different subdivisions is implicated in different expressions of fear responses in these quails [75].

\section{Summarizing Remarks}

The wild stem species of domesticated poultry are characterized by a balanced genome which results in a more or less homogenous outer appearance, physiology, and behavior. Domestication has altered gene frequencies in favor of traits that are advantageous for living in a man-made environment. As a result, hundreds of breeds, particularly in chicken and pigeons, have been established, and some of them are well known for brain and behavioral alterations. All of these traits are gene based, but some of them depend on an interaction of a genetic basis and an individual life history (learning).

Evolution can be characterized as adaptive alteration in gene frequencies too, and sexual behavior including femaleguided mate choice stabilizes this alteration. This may lead to a new species. Domestication of poultry can lead to new species as well or at least to species which are on the way to a new species. This renders investigating diversity in domestic poultry as being a model for evolutionary speciation.

The term "artificial selection" stresses the fact that man seemingly selects sexual mates in contrast to nature where sexual mates come together freely. Thus, artificial selection seems not to be compatible with the biological species concept, and as a consequence, artificial selection could not be said to contribute to speciation. The investigation of sexual behavior in WCP described above has shown that artificial and natural (sexual) selections are not incompatible at all. It can be assumed that at least in domestic chicken, mate choice is characterized by two steps. The first step is a (pre)selection of mates by the breeder. The second step is a mutual acceptance of this preselection by the selected individuals themselves, preferably by the female. Creating a new breed 
such as WCP seems to be a model of allopatric speciation, and if the breed is established, it will be maintained even under sympatric conditions. Surely, what has been investigated in WCP will be confirmed if other breeds are studied. Breeding history and the strength of selection render it probable that, for example, homing pigeons might have a species-like status among pigeons breeds.

A slightly different problem is to what extent artificial insemination annuls natural (sexual) selection. Nowadays, it is common usage in animal breeding and plays a dominant role in breeding chicken for economic purposes. However, even in this situation, it cannot be excluded that pre- and particularly postzygotic isolation mechanisms still work and do have an impact on offspring numbers [76, 77].

In our review, we mainly deal with so-called fancy poultry. But generally, poultry has a very long history of domestication, and many have argued that artificial selection has led to genetic selection for breeds that are better adapted to particularly commercial farming. This is apparently true. Domesticated breeds have different pituitary functioning from their wild counterparts which leads to another approach and avoidance behavior as well as imprinting behavior in comparison to the wild forms [78]. Thus, they are less fearful and additionally, for example, more amenable to accepting new foods, less stressed by closer group contact, and so forth. We listed a lot of more changes in behavior and as well morphology above. But it is a question of degree, not absolutes. Domestication shows an evolutionary process fastforward, but it is still in progress and not already finished (and probably never will be). This should be considered by the different forms of commercial farming and housing conditions. Fortunately, it is becoming increasingly recognized that, for example, understanding the cognitive abilities of animals is essential to issues of animal welfare.

Meanwhile, the breeds of the so-called "fancy poultry" come more and more into the focus of poultry researchers. Nevertheless, during domestication, extensive genetic diversity has accumulated in the domestic poultry, particularly fancy poultry, and this diversity is displayed by the many breeds and strains differing in their phenotypes which are the products of many genetic, environmental, and management regimes. Thus, these breeds represent a resource of genes for future breeding (as well of commercial lines) and research purposes, and in terms of biodiversity conservation and utilization, these genetic resources require further identification and evaluation. Since the beginning of the new millennium, researchers try to assess the biodiversity at the molecular level in a wide range of poultry (particularly chicken) populations [79-81], and surely the next years will bring a lot of more detailed knowledge about fancy poultry, as well as efforts for considering old and traditional breeds as a cultural and historical heritage.

\section{Acknowledgments}

The authors would like to thank Michael von Lüttwitz for providing the photographs of the breeds Araucana and Indian Runner Duck. Thanks are due as well to the Scientific Poultry
Yard (Bruno-Duerigen-Institute, Rhein-Kreis-Neuss, Germany) who gave us the opportunity for making pictures of its breeds.

\section{References}

[1] E. B. Hale, "Domestication and the evolution of behaviour," in The Behaviour of Domestic Animals, E. S. E. Hafez, Ed., pp. 2242, Tindall and Cassell, London, UK, 1969.

[2] E. O. Price, "Behavioral development in animals undergoing domestication," Applied Animal Behaviour Science, vol. 65, no. 3, pp. 245-271, 1999.

[3] E. O. Price, Animal Domestication and Behavior, CAB International, Wallingford, UK, 2002.

[4] H. Hemmer, Domestication: The Decline of Environmental Appreciation, Cambridge University Press, Cambridge, UK, 1983.

[5] C. Darwin, On the Origin of Species by Means of Natural Selection, or the Proservation of Favoured Races in the Struggle for Life, John Murray, London, UK, 1859.

[6] C. Darwin, The Variation of Animals and Plants under Domestication, John Murray, London, UK, 1868.

[7] I. Tiemann and G. Rehkämper, "Effect of artificial selection on female choice among domesticated chickens Gallus gallus f.d," Poultry Science, vol. 88, no. 9, pp. 1948-1954, 2009.

[8] W. Herre and M. Röhrs, Haustiere-zoologisch gesehen, Gustav Fischer, Stuttgart, Germany, 1990.

[9] E. Mayr, Animal Species and Evolution, The Belknap Press of Harvard University Press, Cambridge, Mass, USA, 1963.

[10] M. A. F. Noor, "Is the biological species concept showing its age?" Trends in Ecology and Evolution, vol. 17, no. 4, pp. 153-154, 2002.

[11] J. A. Coyne, H. A. Orr, and H. A., Speciation, Sinauer Associates, Sunderland, Mass, USA, 2004.

[12] J. Maynard-Smith, The Theory of Evolution, Cambridge University Press, Cambridge, Mass, USA, 1993.

[13] P. Ebinger, "Zur Hirn-Körpergewichtsbeziehung bei Wölfen und Haushunden sowie Haushundrassen," Zeitschrift für Säugetierkunde, vol. 45, pp. 148-153, 1980.

[14] P. Ebinger, "Domestication and plasticity of brain organization in mallards (Anas platyrhynchos f.d.)," Brain, Behavior and Evolution, vol. 45, no. 5, pp. 286-300, 1995.

[15] E. S. E. Hafez, Adaptation of Domestic Animals, Lea \& Febiger, Philadelphia, Pa, USA, 1968.

[16] G. Rehkämper, E. Haase, and H. D. Frahm, "Allometric comparison of brain weight and brain structure volumes in different breeds of the domestic pigeon, Columba livia f.d. (fantails, homing pigeons, strassers)," Brain, Behavior and Evolution, vol. 31, no. 3, pp. 141-149, 1988.

[17] G. Rehkämper, H. D. Frahm, and J. Cnotka, "Mosaic evolution and adaptive brain component alteration under domestication seen on the background of evolutionary theory," Brain, Behavior and Evolution, vol. 71, no. 2, pp. 115-126, 2008.

[18] K. R. Kretchmer and M. W. Fox, "Effects of domestication on animal behaviour," Veterinary Record, vol. 96, no. 5, pp. 102-108, 1975.

[19] R. Sossinka, "Domestication in birds", in Avian Biology, D. S. Farner, Ed., vol. 6, pp. 373-403, Academic Press, New York, NY, USA, 1982. 
[20] E. O. Price, "Behavioral genetics and the process of domestication," in Genetics and the Behavior of Domestic Animals, T. Grandin, Ed., pp. 31-65, Academic Press, San Diego, Calif, USA, 1998.

[21] S. Wright, "The relationship of livestock breeding to theories of evolution," Journal of Animal Sciences, vol. 46, pp. 1192-1200, 1978.

[22] R. D. Crawford, Poultry Breeding and Genetics, Elsevier, Amsterdam, The Netherlands, 1990.

[23] R. Boice, "Domestication," Psychological Bulletin, vol. 80, no. 3, pp. 215-230, 1973.

[24] J. Diamond, "Evolution, consequences and future of plant and animal domestication," Nature, vol. 418, no. 6898, pp. 700-707, 2002.

[25] F. E. Zeuner, A History of Domesticated Animals, Hutchinson \& Co Trust Company Limited, London, UK, 1963.

[26] D. Kruska, "Domestikationsbedingte Hirngößenänderungen bei Säugetieren," Zeitschrift für Zoologie, Systematik und Evolutionsforschung, vol. 18, pp. 161-195, 1980.

[27] P. Ebinger, H. DeMacedo, and M. Röhrs, "Hirngrößenänderungen von Wild- zum Hausmeerschweinchen," Zeitschrift für Zoologie, Systematik und Evolutionsforschung, vol. 22, pp. 77-80, 1984.

[28] K. Senglaub, "Das Kleinhirn der Vögel in Beziehung zu phylogenetischer Stellung, Lebensweise und Körpergröße, nebst Beiträgen zum Domestikationsproblem," Zeitschrift für Wissenschaftliche Zoologie, vol. 169, pp. 1-63, 1960.

[29] L. Rogers, The Development of Brain and Behaviour in the Chicken, CAB International, Wallingford, UK, 1995.

[30] J. Clutton-Brock, Domesticated Animals from Early Times, British Museum (Natural History), Heinemann, London, UK, 1981.

[31] A. Sheppy, "The colour of domestication and the designer chicken," Optics and Laser Technology, vol. 43, no. 2, pp. 295301, 2011.

[32] G. Rehkämper, E. Kart, H. D. Frahm, and C. W. Werner, "Discontinuous variability of brain composition among domestic chicken breeds," Brain, Behavior and Evolution, vol. 61, no. 2, pp. 59-69, 2003.

[33] D. Brothwell, "Roman evidence of a crested form of domestic fowl, as indicated by a skull showing associated cerebral hernia," Journal of Archaeological Science, vol. 6, no. 3, pp. 291-293, 1979.

[34] H. D. Frahm and G. Rehkämper, "Allometric comparison of the brain and brain structures in the white crested polish chicken with uncrested domestic chicken breeds," Brain, Behavior and Evolution, vol. 52, no. 6, pp. 292-307, 1998.

[35] I. Tiemann and G. Rehkämper, "Rassenunterschiede bei Haushühnern (Gallus gallus f.d.) bei klassischer und operanter Konditionierung in der Skinner-Box," Acta Biologica Benrodis, vol. 13, pp. 231-240, 2007.

[36] I. Tiemann and G. Rehkämper, "Breed-specific companionsInter-individual distances reflect isolating mechanisms within domesticated chickens (Gallus gallus f.d.)," Brain Research Bulletin, vol. 76, no. 3, pp. 300-303, 2008.

[37] I. Tiemann and G. Rehkämper, "Evolutionary pets: offspring numbers reveal speciation process in domesticated chickens," PloS ONE, vol. 7, no. 8, Article ID e41453, 2012.

[38] R. G. Somes, "Ear-tufts: a skin structure mutation of the Araucana fowl," Journal of Heredity, vol. 69, no. 2, pp. 91-96, 1978.
[39] A. Sahl, Akustische Wahrnehmung und assoziierte kognitive Leistungen beim Hausgeflügel [Diploma thesis], University of Düsseldorf, Düsseldorf, Germany, 2008.

[40] P. M. Bennett and P. H. Harvey, "Relative brain size and ecology in birds," Journal of Zoology, vol. 207, pp. 151-169, 1985.

[41] A. N. Iwaniuk and P. L. Hurd, "The evolution of cerebrotypes in birds," Brain, Behavior and Evolution, vol. 65, no. 4, pp. 215-230, 2005.

[42] R. F. Howard and A. Moore, A Complete Checklist of the Birds of the World, Academic Press, London, UK, 1991.

[43] R. O. Hawes, "Pigeons," in Evolution of Domesticated Animals, I. L. Mason, Ed., pp. 351-356, Longman, New York, NY, USA, 1984.

[44] R. F. Johnston and M. Janiga, Feral Pigeons, Oxford University Press, New York, NY, USA, 1995.

[45] P. Ebinger and R. Löhmer, "Comparative quantitative investigations on brains of rock doves, domestic and urban pigeons (Columba 1. livia)," Zeitschrift für Zoologie, Systematik und Evolutionsforschung, vol. 22, pp. 136-145, 1984.

[46] E. Visalberghi, A. Foa, N. E. Baldaccini, and E. Alleva, "New experiments on the homing ability of the rock pigeon," Monitore Zoologico Italiano (NS), vol. 12, pp. 199-209, 1978.

[47] F. Papi, P. Ioalé, V. Fiaschi, S. Benvenuti, and N. E. Baldaccini, "Olfactory navigation of pigeons: the effect of treatment with odorous air currents," Journal of Comparative Physiology, vol. 94, no. 3, pp. 187-193, 1974.

[48] R. A. Barton and P. H. Harvey, "Mosaic evolution of brain structure in mammals," Nature, vol. 405, no. 6790, pp. 10551058,2000

[49] R. Lande, "Models of speciation by sexual selection on polygenic traits," Proceedings of the National Academy of Sciences of the United States of America, vol. 78, no. 6 I, pp. 3721-3725, 1981.

[50] J. Mehlhorn and G. Rehkämper, "Neurobiology of the homing pigeon-a review," Naturwissenschaften, vol. 96, no. 9, pp. 1011$1025,2009$.

[51] D. S. Moore, The Dependent Gene: The Fallacy of Nature versus Nurture, Smithsonians Institution Press, Washington, DC, USA, 2003.

[52] J. Cnotka, M. Möhle, and G. Rehkämper, "Navigational experience affects hippocampus size in homing pigeons," Brain, Behavior and Evolution, vol. 72, no. 3, pp. 233-238, 2008.

[53] J. Mehlhorn, B. Haastert, and G. Rehkämper, "Asymmetry of different brain structures in homing pigeons with and without navigational experience," Journal of Experimental Biology, vol. 213, no. 13, pp. 2219-2224, 2010.

[54] T. L. Vincent and J. S. Brown, Evolutionary Game Theory, Natural Selection, and Darwinian Dynamics, Cambridge University Press, Cambridge, UK, 2005.

[55] P. Ebinger and R. Löhmer, "Relationship of brain weight and body weight in mallards," Zoologischer Anzeiger, vol. 214, pp. 285-290, 1985.

[56] D. B. Miller, "Social displays of mallard ducks (Anas platyrhynchos): effects of domestication," Journal of Comparative and Physiological Psychology, vol. 91, no. 2, pp. 221-232, 1977.

[57] J. Cnotka, H. D. Frahm, and G. Rehkämper, "Intracranial fat bodies and their influence on brain composition and behaviour in domestic ducks with feather crests (3 case studies)," Deutsche Tierärztliche Wochenschrift, vol. 113, no. 1, pp. 27-31, 2006.

[58] J. Cnotka, H. D. Frahm, A. Mpotsaris, and G. Rehkämper, "Motor incoordination, intracranial fat bodies, and breeding 
strategy in Crested ducks (Anas platyrhynchos f.d.)," Poultry Science, vol. 86, no. 9, pp. 1850-1855, 2007.

[59] T. Bartels and N. Kummerfeld, Abschlussbereicht zum Forschungsauftrag 96 HS 046, Untersuchungen zur Haubenbildung bei Hausenten, Bundesanstalt für Landwirtschaft und Ernährung, Frankfurt a. M., Bonn, Germany, 2001.

[60] T. Bartels, J. Brinkmeier, S. Portmann et al., "Intrakraniale Fettkörper bei Hausenten (Anas platyrhynchos f.d.)," Tierärztliche Praxis, vol. 29, pp. 384-390, 2001.

[61] J. Cnotka, I. Tiemann, H. D. Frahm, and G. Rehkämper, "Unusual brain composition in Crested Ducks (Anas platyrhynchos f.d.)-including its effect on behavior and genetic transmission," Brain Research Bulletin, vol. 76, no. 3, pp. 324-328, 2008.

[62] J. Mehlhorn and G. Rehkämper, "Brain alterations, their impact on behavior and breeding strategy in Crested Ducks (Anas platyrhynchos f.d.)," Archiv für Geflügelkunde, vol. 74, pp. 203209, 2010.

[63] S. J. Gould, The Structure of Evolutionary Theory, The Belknap Press of Harvard University, Cambridge, Mass, USA, 2002.

[64] T. F. Savage, "Mutations and major variants in turkeys," in Poultry Breeding and Genetics, R. D. Crawford, Ed., pp. 317-331, Elsevier, Amsterdam, The Netherlands, 1990.

[65] P. Ebinger, M. Röhrs, and J. Pohlenz, "Reductions of brain and eye weight in the wild and domestic turkey (Meleagris gallopavo)," Zeitschrift für Zoologie, Systematik und Evolutionsforschung, vol. 27, pp. 142-148, 1989.

[66] P. Edinger and M. Rohrs, "Volumetric analysis of brain structures, especially of the visual system in wild and domestic turkeys (Meleagris gallopavo)," Journal of Brain Research, vol. 36, no. 2, pp. 219-228, 1995.

[67] A. Portmann, "Études sur la cérébralisation chez les oiseaux I," Alauda, vol. 14, pp. 2-20, 1946.

[68] G. Rehkämper, H. D. Frahm, and K. Zilles, "Quantitative development of brain and brain structures in birds (Galliformes and Passeriformes) compared to that in mammals (Insectivores and Primates)," Brain, Behavior and Evolution, vol. 37, no. 3, pp. 125-143, 1991.

[69] R. D. Crawford, “Turkeys," in Evolution of Domesticated Animals, I. L. Mason, Ed., pp. 325-334, Longman, New York, NY, USA, 1984.

[70] P. Ebinger and R. Löhmer, "A volumetric comparison of brains between greylag geese (Anser anser L.) and domestic geese," Journal für Hirnforschung, vol. 28, no. 3, pp. 291-299, 1987.

[71] R. O. Hawes, "Mutations and major variants in geese," in Poultry Breeding and Genetics, R. D. Crawford, Ed., Elsevier, Amsterdam, The Netherlands, 1990.

[72] A. D. Mills, L. L. Crawford, M. Domjan, and J. M. Faure, "The behavior of the Japanese or domestic quail Coturnix japonica," Neuroscience and Biobehavioral Reviews, vol. 21, no. 3, pp. 261281, 1997.

[73] K. M. Cheng and M. Kimura, "Mutations and major variants in Japanese quail," in Poultry Breeding and Genetics, R. D. Crawford, Ed., Elsevier, Amsterdam, The Netherlands, 1990.

[74] W. Bessei, R. B. Jones, and J. M. Faure, "Ease of capture by human beings of Japanes quail (Coturnix corturnix japonica) genetically selected for different activity levels," Archiv für Geflügelkunde, vol. 47, pp. 137-143, 1983.

[75] H. Saint-Dizier, P. Constantin, D. C. Davies, C. Leterrier, F. Lévy, and S. Richard, "Subdivisions of the arcopallium/posterior pallial amygdala complex are differentially involved in the control of fear behaviour in the Japanese quail," Brain Research Bulletin, vol. 79, no. 5, pp. 288-295, 2009.
[76] T. D. Price and M. M. Bouvier, "The evolution of F1 postzygotic incompatibilities in birds," Evolution, vol. 56, no. 10, pp. 20832089, 2002.

[77] D. A. Lijtmaer, B. Mahler, and P. L. Tubaro, "Hybridization and postzygotic isolation patterns in pigeons and doves," Evolution, vol. 57, no. 6, pp. 1411-1418, 2003.

[78] J. T. Martin, "Embryonic pituitary adrenal axis, behavior development and domestication in birds," Integrative and Comparative Biology, vol. 18, no. 3, pp. 489-499, 1978.

[79] S. Weigend and M. N. Romanov, "The world watch list for domestic animal diversity in the context of conservation and utilisation of poultry biodiversity," World's Poultry Science Journal, vol. 58, no. 4, pp. 411-430, 2002.

[80] J. Hillel, M. A. M. Groenen, M. Tixier-Boichard et al., "Biodiversity of 52 chicken populations assessed by microsatellite typing of DNA pools," Genetics Selection Evolution, vol. 35, no. 5, pp. 533-557, 2003.

[81] H. Sawai, H. L. Kim, K. Kuno et al., “The origin and genetic variation of domestic chickens with special reference to junglefowls Gallus g. gallus and G. varius," PLoS ONE, vol. 5, no. 5, Article ID e10639, 2010. 

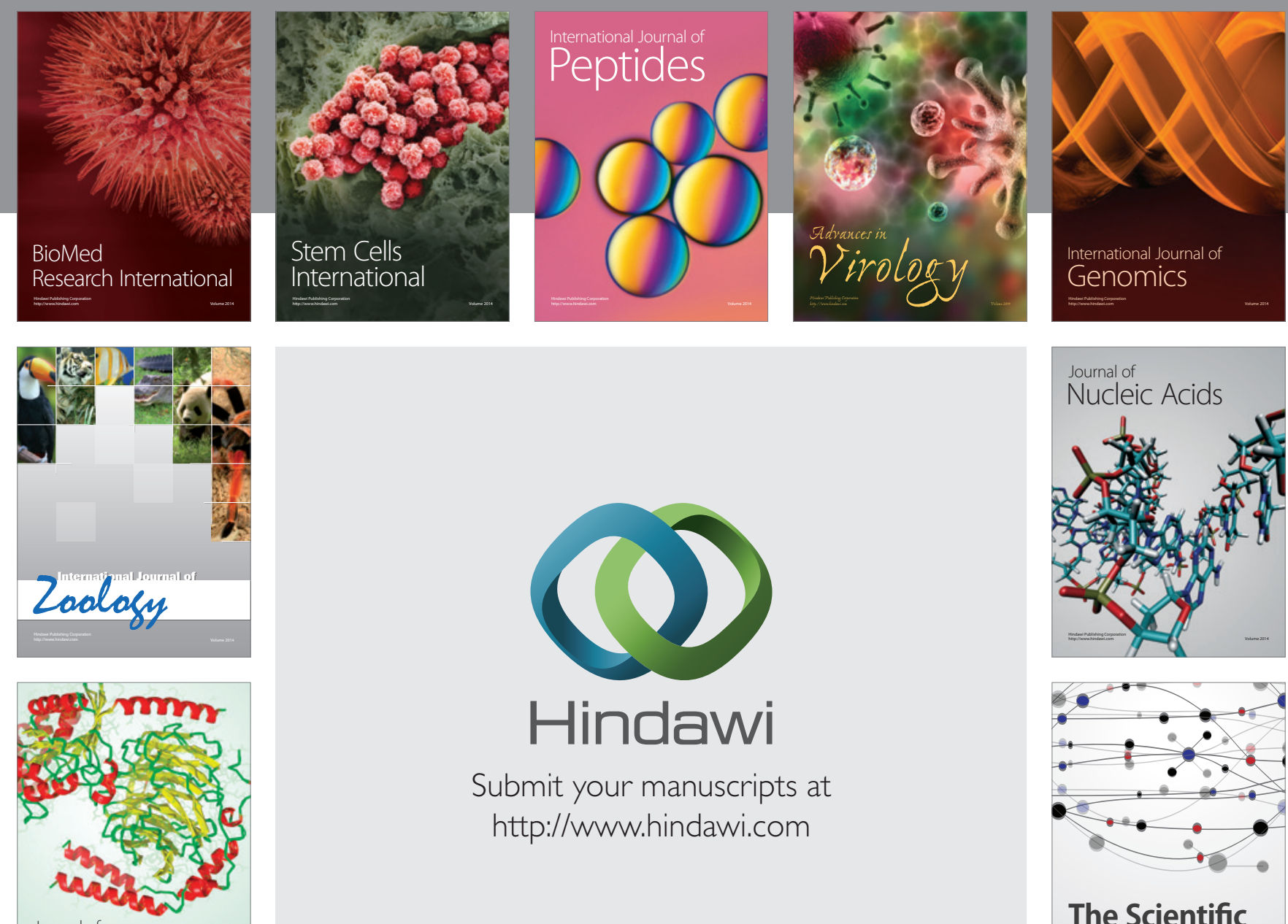

Submit your manuscripts at

http://www.hindawi.com

Journal of
Signal Transduction
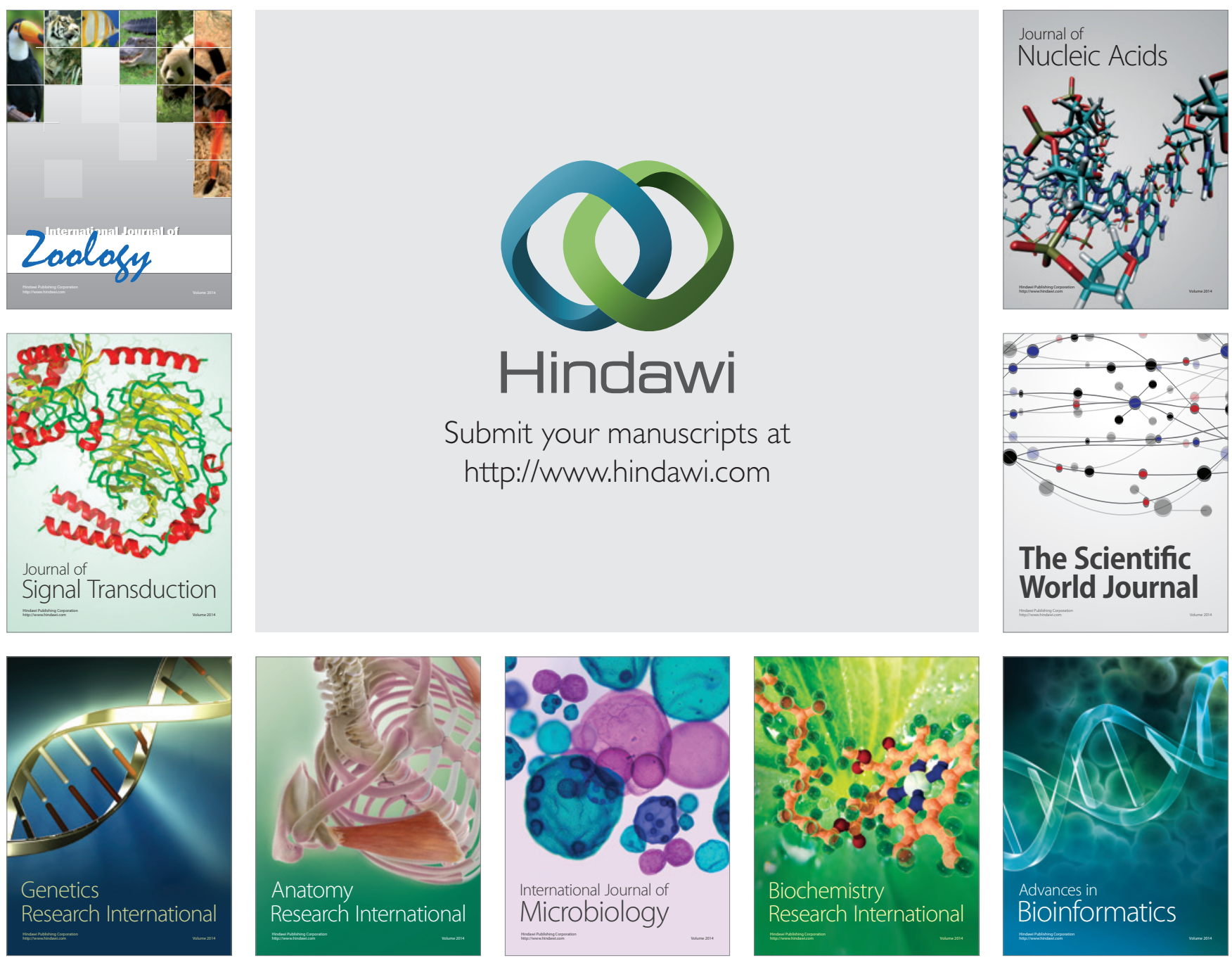

The Scientific World Journal
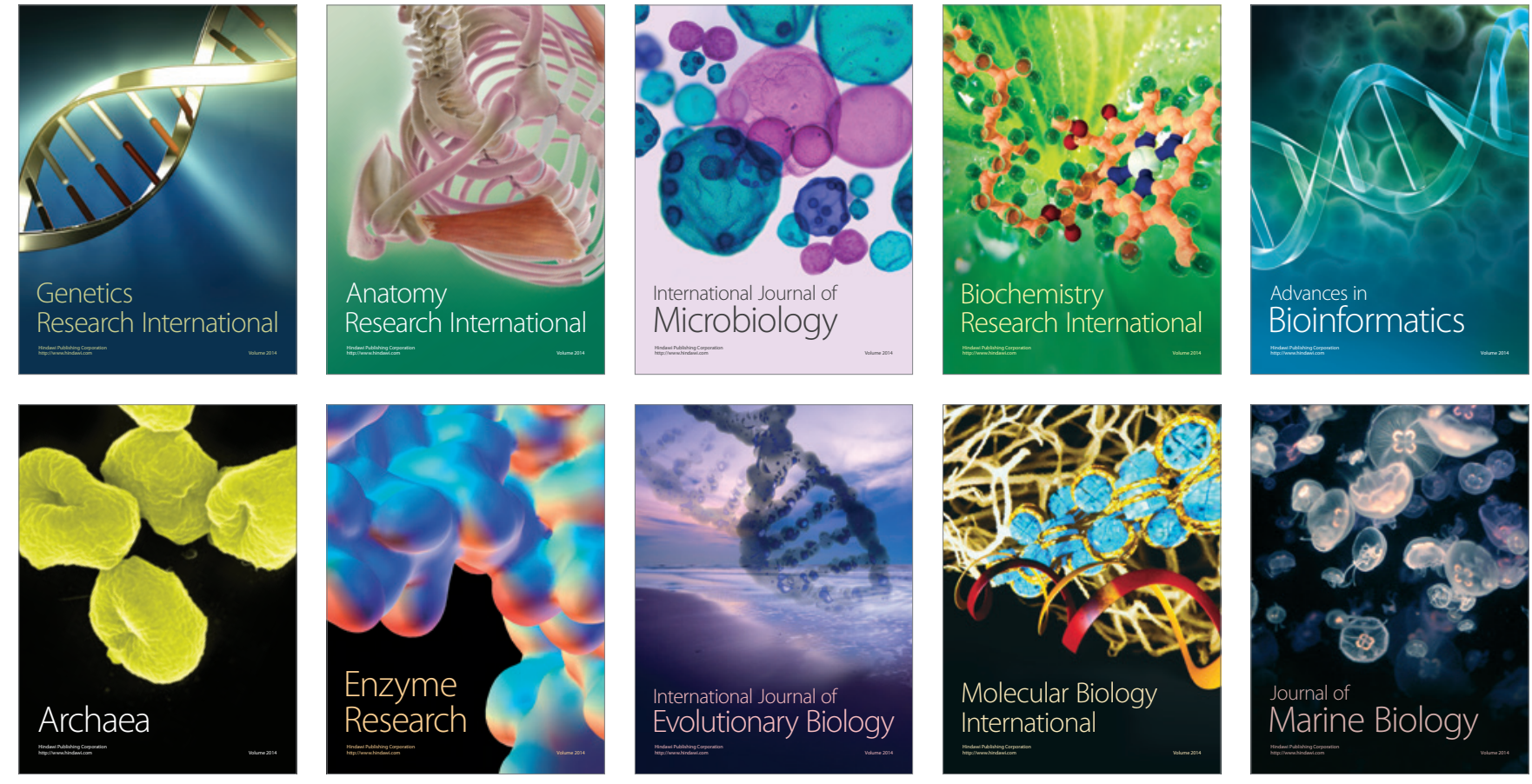